\title{
Short communication: Validation of methods for practically evaluating failed passive transfer of immunity in calves arriving at a veal facility
}

\author{
D. L. Renaud, T. F. Duffield, S. J. LeBlanc, and D. F. Kelton ${ }^{1}$ \\ Department of Population Medicine, University of Guelph, Guelph, Ontario N1G 2W1, Canada
}

\begin{abstract}
Providing a sufficient quantity of high-quality colostrum to male and female calves soon after birth is critical to reduce the risk of disease and mortality. Practical tests have not been validated to determine failed passive transfer of immunity upon arrival at veal facilities. There are many challenges to validation, including the lack of information on the age of the calf and the high prevalence of dehydration. The objective of this study was to validate a semiquantitative $\operatorname{IgG}$ antibody test using whole blood and a digital refractometer using serum to determine passive transfer of immunity status. A total of 149 Holstein calves were evaluated upon arrival at a milk-fed veal facility for dehydration status and had blood drawn to evaluate passive transfer of immunity. Serum IgG determined by radial immunodiffusion was used as the gold standard for the validation of the tests, and a cut-off point of $<1,000 \mathrm{mg} / \mathrm{dL}$ of IgG was used to indicate failed passive transfer of immunity. Serum total protein (STP) was evaluated using a digital refractometer (Misco Palm Abbe no. PA202x, Misco, Solon, $\mathrm{OH}$ ), and a semiquantitative test (ZAPvet Bovine IgG test, NOWDiagnostics, Toronto, Ontario, Canada) was used on whole blood. A nonparametric receiver operating characteristic curve was generated to compare STP and IgG levels. Sensitivity, specificity, positive predictive values, and negative predictive values were calculated for STP and the semiquantitative IgG test. A total of 31 calves (21\%) had serum IgG $<1,000 \mathrm{mg} / \mathrm{dL}$. Twelve percent of calves were showing signs of clinical dehydration when assessed upon arrival. The serum total protein (STP) was very well correlated with the concentration of $\operatorname{IgG}\left(\mathrm{R}^{2}=0.75\right)$. The STP cut point to determine passive transfer was $\geq 5.1 \mathrm{~g} / \mathrm{dL}$, yielding a sensitivity of $84 \%$ and a specificity of $90 \%$. The semiquantitative antibody test on
\end{abstract}

Received March 9, 2018.

Accepted June 4, 2018.

${ }^{1}$ Corresponding author: dkelton@uoguelph.ca whole blood performed poorly, with a sensitivity of $77 \%$ and a specificity of $44 \%$. This study demonstrates that serum total protein is a reliable measure for evaluating passive transfer of immunity and can be used despite a high prevalence of dehydration.

Key words: male calf, serum total protein, failed transfer of passive immunity

\section{Short Communication}

Providing a sufficient quantity of high-quality colostrum to newborn calves is an integral component of calf management because failed passive transfer of immunity (FPT) in calves is associated with an increased risk of disease (Postema and Mol, 1984; Godden, 2008; Pardon et al., 2015) and mortality (Renaud et al., 2018). Despite the known importance of feeding colostrum, FPT is estimated to be common among calves entering the veal industry (Wilson et al., 2000; Pardon et al., 2015).

No rapid point-of-care tests have been validated to assess passive transfer of immunity upon arrival to veal facilities, making it difficult for producers to identify high-risk calves upon arrival and avoid source dairy farms that may have poor colostrum management. Radial immunodiffusion (RID) is the gold standard method for determining passive transfer of immunity (Beam et al., 2009); however, blood must be sent to a referral laboratory for this technique to be performed. Serum total protein (STP) determined by refractometry has been shown to be well correlated with immunoglobulin concentrations measured by RID in dairy calves (Naylor and Kronfeld, 1977), but it has not been validated in calves upon arrival at veal facilities, where the age of the calves is unknown and many calves are dehydrated (Renaud et al., 2018). A new semiquantitative antibody test (ZAP test) has been validated using serum from dairy calves; however, it has not been used on whole blood (Elsohaby and Keefe, 2015). Utilizing this test on whole blood may allow for a quicker point-of-care decision and reduce the amount of time required to determine passive transfer of immunity status. The objective of this study was to validate a semiquantitative IgG test (ZAPvet Bovine IgG test, NOWDiagnostics, 
Table 1. Description and prevalence of clinical dehydration scores upon arrival to a milk-fed veal facility $(\mathrm{n}=140)$

\begin{tabular}{|c|c|c|}
\hline $\begin{array}{l}\text { Dehydration } \\
\text { score }\end{array}$ & Description & $\begin{array}{l}\text { Prevalence, } \% \\
\quad(\mathrm{n})\end{array}$ \\
\hline 0 & Skin tent returns to normal in $<2 \mathrm{~s}$, eyes bright and alert, strong suckle ( $\leq 5 \%$ dehydrated) & $87.9(123)$ \\
\hline 2 & Good suckle, eyes slightly sunken, skin tent returns to normal in $2-4 \mathrm{~s}$ ( $8-10 \%$ dehydrated) & $1.4(2)$ \\
\hline 3 & $\begin{array}{l}\text { Mild depression, sternal recumbency, moderately sunken eyes, skin tent returns to normal in } 4-8 \mathrm{~s} \text {, } \\
\text { tacky mucus membranes with poor suckle }(10-12 \% \text { dehydrated })\end{array}$ & $0(0)$ \\
\hline 4 & $\begin{array}{l}\text { Profound depression, absent suckle, lateral recumbency, eyes deeply sunken, skin tent returns to } \\
\text { normal in }>8-10 \mathrm{~s} \text {, dry mucous membranes ( }>12 \% \text { dehydrated) }\end{array}$ & $0(0)$ \\
\hline
\end{tabular}

Toronto, Ontario, Canada) using whole blood and a digital refractometer (Misco Palm Abbe no. PA202x, Misco, Solon, $\mathrm{OH}$ ) using serum for determination of FPT.

This study was conducted in cooperation with a milkfed veal producer and in accordance with the University of Guelph Animal Care Committee requirements (animal use protocol no. 3453). A total of 149 Holstein male calves were sampled in August 2016 upon arrival at a milk-fed veal farm.

For sample size calculations, the prevalence of FTP $(<1,000 \mathrm{mg}$ of $\mathrm{IgG} / \mathrm{dL})$ upon arrival was expected to be $38 \%$ (Trotz-Williams et al., 2008), and the sensitivity and specificity of STP as a test to identify calves with FTP were predicted to be 85 and $75 \%$, respectively. Using the method described by Buderer (1996) and assuming that the clinically acceptable width of the $95 \%$ confidence intervals for sensitivity and specificity was to be no larger than $10 \%$, the sample size required was determined to be 123 calves.

Calves were evaluated for dehydration by a single assessor (Renaud et al., 2018) using skin tent, attitude, and suckle reflex (Table 1). Calves were considered dehydrated if they had a dehydration score of $\geq 1$. Whole blood was collected by jugular venipuncture using a 20-gauge, 1-inch hypodermic needle into sterile plastic vacuum tubes without anticoagulant and into a sterile 3 -mL syringe without anticoagulant. Immediately following collection, whole blood was dispensed according to manufacturer instructions onto the semiquantitative IgG test using a syringe. The test was kept on a flat surface and read by comparing the intensity of the test line against the referent line 15 to $20 \mathrm{~min}$ following the application of the whole blood. If the ZAPvet test line was lighter in color than the referent line, the calf was considered to have FPT. However, if the test line was similar or darker in color than the referent line, the calf was considered to have successful passive transfer of immunity (Elsohaby and Keefe, 2015). The vacuum tube blood samples were allowed to clot and then were centrifuged at $1,500 \times g$ for $15 \mathrm{~min}$ at approximately $20^{\circ} \mathrm{C}$. Serum was separated and placed on the measuring surface of the digital refractometer to estimate STP. The remainder of the separated serum was stored at $-20^{\circ} \mathrm{C}$ until submission to the Saskatoon Colostrum Company (Saskatoon, SK, Canada) for measurement of IgG by RID as described by Chelack et al. (1993).

All statistical analyses were completed using Stata 14 (StataCorp LLC, College Station, TX). Data were imported from Microsoft Excel (Microsoft Corp., Redmond, WA) into Stata 14 and checked for completeness. Serum IgG determined by RID was used as the gold standard for the validation of the tests, and a cut-off point of $<1,000 \mathrm{mg} / \mathrm{dL}$ of $\mathrm{IgG}$ was used to indicate FPT (Godden, 2008). A nonparametric receiver operating characteristic curve was generated to compare STP and IgG levels and to determine the sensitivity and specificity of STP to classify cases of FPT (Dohoo et al., 2009). The cut-off point for STP was selected to weigh sensitivity and specificity equally to limit the effect of both false-positive and false-negative diagnoses (Florkowski, 2008). Sensitivity, specificity, positive predictive value, and negative predictive value were also calculated using the ZAPvet Bovine IgG. To evaluate the correlation between RID and STP, simple linear regression analysis was conducted with STP as the predictor and IgG concentration as the outcome of interest. Using a $t$-test, the STP in dehydrated calves (dehydration score $\geq 1$ ) and the STP in calves that were not dehydrated were compared to evaluate the effect of dehydration on STP.

A total of 31 calves (21\%) had serum IgG $<1,000$ $\mathrm{mg} / \mathrm{dL}$. The mean $( \pm \mathrm{SD})$ concentration of $\operatorname{IgG}$ in the serum samples $(\mathrm{n}=149)$ was $1,989 \mathrm{mg} / \mathrm{dL}( \pm 1,057$ $\mathrm{mg} / \mathrm{dL}$ ), ranging from 110 to $5,730 \mathrm{mg} / \mathrm{dL}$. The mean $( \pm \mathrm{SD})$ concentration of STP $(\mathrm{n}=149)$ was $5.6 \mathrm{~g} / \mathrm{dL}$ $( \pm 0.7 \mathrm{~g} / \mathrm{dL})$, ranging from 4.1 to $7.9 \mathrm{~g} / \mathrm{dL}$. The concentration of STP was well correlated with the concentra- 
Table 2. Test characteristics relative to serum IgG measured by radial immunodiffusion of a semiquantitative IgG test (ZAPvet Bovine IgG test, NOWDiagnostics, Toronto, ON, Canada) using whole blood and by a digital refractometer (Misco Palm Abbe no. PA202x, Misco, Solon, OH) using serum from 149 Holstein calves arriving at a veal facility

\begin{tabular}{lccccc}
\hline Test & $\begin{array}{c}\text { Cut point } \\
(\mathrm{g} / \mathrm{dL})\end{array}$ & $\begin{array}{c}\text { Sensitivity } \\
(\%)\end{array}$ & $\begin{array}{c}\text { Specificity }^{2} \\
(\%)\end{array}$ & $\begin{array}{c}\mathrm{PPV}^{3} \\
(\%)\end{array}$ & $\begin{array}{c}\mathrm{NPV}^{4} \\
(\%)\end{array}$ \\
\hline ZAPvet & - & 77 & 44 & 27 & 87 \\
Digital refractometer & 5.1 & 84 & 90 & 68 & 96 \\
\hline
\end{tabular}

${ }^{1}$ The probability of testing positive for failed passive transfer of immunity (FPT) using the ZAPvet test or digital refractometer given that the calf has a level of $\operatorname{IgG}<1,000 \mathrm{mg} / \mathrm{dL}$ as measured by radial immunodiffusion.

${ }^{2}$ The probability of testing negative for FPT using the ZAPvet test or digital refractometer given that the calf has a level of $\mathrm{IgG} \geq 1,000 \mathrm{mg} / \mathrm{dL}$ as measured by radial immunodiffusion.

${ }^{3}$ Positive predictive value: the probability that the calf has a level of $\operatorname{IgG}<1,000 \mathrm{mg} / \mathrm{dL}$ given that the calf tested positive for FPT according to the ZAPvet test or digital refractometer.

${ }^{4}$ Negative predictive value: the probability that the calf has a level of $\operatorname{IgG} \geq 1,000 \mathrm{mg} / \mathrm{dL}$ given that the calf tested negative for FPT according to the ZAPvet test or digital refractometer.

tion of IgG, with STP explaining $75 \%$ of the variation in the level of IgG (Figure 1). The receiver operating characteristic curve for these data had an area under the curve of 0.92 , which indicates the probability that a randomly selected positive individual has a greater score than a randomly selected negative individual (Dohoo et al., 2009). Assuming that the optimal cut-off point is the point where sensitivity and specificity are at a maximum, the cut-off point for passive transfer of immunity was determined to be a score of $\geq 5.1 \mathrm{~g} / \mathrm{dL}$, which correctly classified $89 \%$ of calves (Dohoo et al., 2009) with an apparent prevalence of FPT of $28 \%$. The test characteristics are summarized in Table 2 .

A total of $17(12 \%)$ calves were identified with clinical dehydration upon arrival (Table 1). Despite the number of calves with dehydration, dehydration did not influence STP levels, with dehydrated and nondehydrated calves having a mean \pm standard deviation concentra-

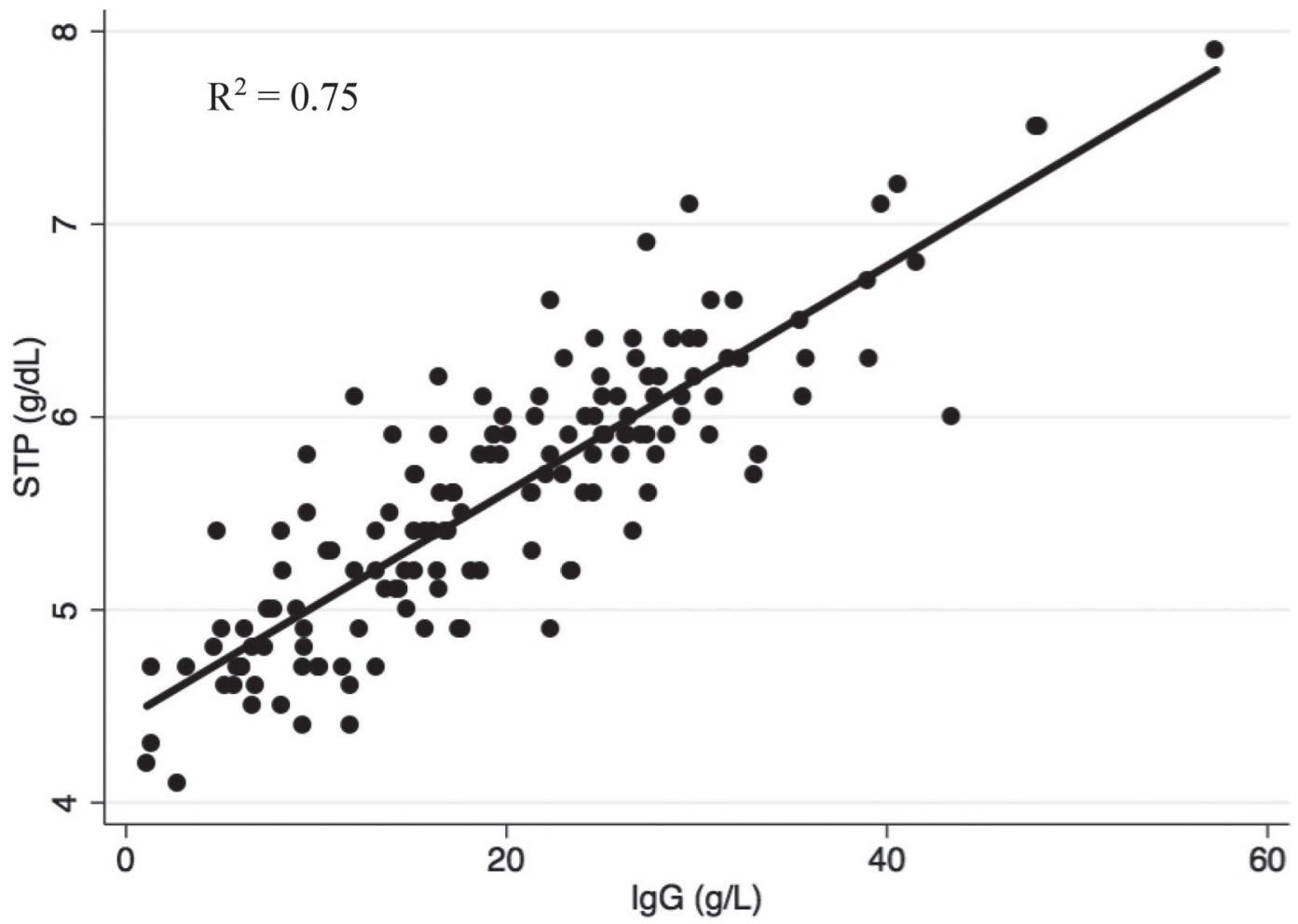

Figure 1. Relationship between serum total protein (STP) and IgG measured in 149 calves upon arrival to a veal facility. 
tion of $5.6 \pm 0.9$ and $5.6 \pm 0.7 \mathrm{~g} / \mathrm{dL}$, respectively $(P$ $=0.87$. As determined by the ZAP test, the apparent prevalence of FPT was $36 \%$ (54/149 calves tested). The test characteristics are summarized in Table 2.

Serum total protein measured by a digital refractometer was found to be a good predictor of the level of $\operatorname{IgG}$ despite dehydration being present upon arrival in more than $10 \%$ of calves. The semiquantitative test on whole blood was found to not be a reliable method for determining passive transfer of immunity status. A possible limitation of the study was the use of a single threshold derived from dairy replacement calves of $<1,000 \mathrm{mg} /$ $\mathrm{dL}$ of IgG for determination of FPT status. Renaud et al. (2018) demonstrated that a higher threshold of $1,670 \mathrm{mg} / \mathrm{dL}$ of $\mathrm{IgG}$ improved the ability to predict mortality. Thus, the traditional threshold of $<1,000$ $\mathrm{mg} / \mathrm{dL}$ may need to be re-evaluated on veal calves to determine what the optimal cut point is for predicting both mortality and morbidity.

Providing a simple and easy test for veal producers is necessary to identify source farms that have colostrum management issues. The RID assay for IgG is time consuming and expensive, thus limiting the ability to practically apply it on farm. The STP of calves can be easily measured and is an excellent on-farm tool for herd monitoring (Weaver et al., 2000). It can also be evaluated without the use of a centrifuge, where the serum is simply allowed to clot (Wallace et al., 2006). Hence, it could be used by veal producers as a mechanism to provide feedback to dairy producers regarding colostrum management to facilitate behavior change. A cut-off point of $5.1 \mathrm{~g} / \mathrm{dL}$ would maximize the sensitivity, thus minimizing the number of false negatives.

It has been speculated that calves suffering from dehydration would have higher STP (Tyler et al., 1996). In our study, clinical dehydration was found in some calves upon arrival but did not influence the level of STP. To better evaluate the true effect of dehydration on STP measured upon arrival, a greater variation in the levels of dehydration and greater sample size are required.

Despite showing efficacy when assessing FPT on serum (Elsohaby and Keefe, 2015), the semiquantitative IgG test used on whole blood was not valuable in identifying veal calves with FPT. The test had moderate sensitivity, but the low specificity would lead to a large number of false positives. Small changes in the intensity of the test line relative to the referent line used indicate FPT and the difficultly in placing the correct volume of blood into the application zone were challenges with the interpretation of the test. Under ideal circumstances, it would have been useful to evaluate this test on both whole blood and serum; however, the number of tests available for this project was limited.

This study demonstrates that, despite calves arriving with clinical dehydration and unknown age, STP is an accurate method for evaluating FPT as identified using RID. It also demonstrates that the semiquantitative IgG test, which has been shown to be accurate when applied to serum, is not sufficiently accurate in determining passive transfer of immunity status when used on whole blood.

\section{ACKNOWLEDGMENTS}

The authors thank the participating producer and NOWDiagnostics. The first author was also supported by Grober Inc. (Cambridge, Ontario, Canada), Veal Farmers of Ontario (Guelph, Ontario, Canada), Dairy Farmers of Ontario (Mississauga, Ontario, Canada), the Ontario Ministry of Agriculture, Food and Rural Affairs, and the Ontario Veterinary College (University of Guelph).

\section{REFERENCES}

Beam, A. L., J. E. Lombard, C. A. Kopral, L. P. Garber, A. L. Winter, J. A. Hicks, and J. L. Schlater. 2009. Prevalence of failure of passive transfer of immunity in newborn heifer calves and associated management practices on US dairy operation. J. Dairy Sci. 92:3973-3980. https://doi.org/10.3168/jds.2009-2225.

Buderer, N. M. F. 1996. Statistical methodology: I. Incorporating the prevalence of disease into the sample size calculation for sensitivity and specificity. Acad. Emerg. Med. 3:895-900. https://doi.org/10 $.1111 /$ j.1553-2712.1996.tb03538.x.

Chelack, B. J., P. S. Morley, and D. M. Haines. 1993. Evaluation of methods for dehydration of bovine colostrum for total replacement of normal colostrum in calves. Can. Vet. J. 34:407-412.

Dohoo, I., W. Martin, and H. Stryhn. 2009. Veterinary Epidemiologic Research. 2nd ed. Screening and Diagnostic Tests. VER Inc., Charlottetown, Prince Edward Island, Canada.

Elsohaby, I., and G. P. Keefe. 2015. Preliminary validation of a calfside test for diagnosis of failure of transfer of passive immunity in dairy calves. J. Dairy Sci. 98:4754-4761.

Florkowski, C. M. 2008. Sensitivity, specificity, receiver-operating characteristic (ROC) curves and likelihood ratios: Communicating the performance of diagnostic tests. Clin. Biochem. Rev. 29:S83-S87.

Godden, S. 2008. Colostrum management for dairy calves. Vet. Clin. North Am. Food Anim. Pract. 24:19-39. https://doi.org/10.1016/ j.cvfa.2007.10.005.

Naylor, J. M., and D. S. Kronfeld. 1977. Refractometry as a measure of the immunoglobulin status of the newborn dairy calf: Comparison with zinc sulfate turbidity test and single radial immunodiffusion. Am. J. Vet. Res. 38:1331-1334.

Pardon, B., J. Alliët, R. Boone, S. Roelandt, B. Valgaeren, and P. Deprez. 2015. Prediction of respiratory disease and diarrhea in veal calves based on immunoglobulin levels and the serostatus for respiratory pathogens measured at arrival. Prev. Vet. Med. 120:169-176. https://doi.org/10.1016/j.prevetmed.2015.04.009.

Postema, H. J., and J. Mol. 1984. Risk of disease in veal calves: Relationships between colostrum-management, serum immunoglobulin levels and risk of disease. Zentralbl. Veterinarmed. A 31:751-762. https://doi.org/10.1111/j.1439-0442.1984.tb01334.x. 
Renaud, D. L., T. F. Duffield, S. J. LeBlanc, D. B. Haley, and D. F. Kelton. 2018. Clinical and metabolic indicators associated with early mortality at a milk-fed veal facility: A prospective case-control study. J. Dairy Sci. 101:2669-2678. https://doi.org/10.3168/ jds.2017-14042.

Trotz-Williams, L., K. Leslie, and A. Peregrine. 2008. Passive immunity in Ontario dairy calves and investigation of its association with calf management practices. J. Dairy Sci. 91:3840-3849. https: //doi.org/10.3168/jds.2007-0898.

Tyler, J. W., D. D. Hancock, S. M. Parish, D. E. Rea, T. E. Besser, S. G. Sanders, and L. K. Wilson. 1996. Evaluation of 3 assays for failure of passive transfer in calves. J. Vet. Intern. Med. 10:304-307.

Wallace, M. M., B. D. Jarvie, N. R. Perkins, and K. E. Leslie. 2006. A comparison of serum harvesting methods and type of refrac- tometer for determining total solids to estimate failure of passive transfer in calves. Can. Vet. J. 47:573-575.

Weaver, D. M., J. W. Tyler, D. C. Vanmetre, D. E. Hostetler, and G. M. Barrington. 2000. Passive transfer of colostral immunoglobulins in calves. J. Vet. Intern. Med. 14:569-577. https://doi.org/10 $.1111 /$ j.1939-1676.2000.tb02278.x.

Wilson, L., J. Smith, D. Smith, D. Swanson, T. Drake, D. Wolfgang, and E. Wheeler. 2000. Characteristics of veal calves upon arrival, at 28 and 84 days, and at the end of the production cycle. J. Dairy Sci. 83:843-854. https://doi.org/10.3168/jds.s0022-0302(00)74948 -4 . 